\title{
Significant Contribution in Healthcare by using IoT
}

\author{
Juhi K. Patgiri, Arindam Mondal, Gitanjali Kaman, Pinki Deori, Vinayak Majhi, Sudip Paul
}

\begin{abstract}
Nowadays, the heart-related disease is rapidly rising. Most patients, in some cases, may not identify their health condition. Even in rural areas, doctors are not available $24 \times 7$. Due to the advancement of modern technology, these diseases can be detected early and can be treated on time. So, the developed device can continuously track the patient's heartbeat and temperature, and the recorded data can be sent to the concerned doctor so that treatment can be provided to the patient. Here the IoT (Internet of Things) is being used for monitoring the patient's health status and send wirelessly to the IoT server. This device can also be monitored from remote places. This device is mainly helpful for aged and disabled people who find it difficult to go to doctors daily or for patients who need continuous monitoring of their health status. The designed hardware will capture the real-time heartrate and temperature value and send the data to the concern IoT server using any mobile or Wi-Fi network having with internet facility. Before sending the data the preprocessing is being done by the attached microcontroller in the respective sensors module. The value sent in the IoT server will be used for generating the online graph through the Application Program Interface (API) that are used in developing the web and mobile application. In this system the authenticated user can view the output trough developed mobile application web application.
\end{abstract}

Keywords : Internet of Things (IoT), Human Heart Rate, Body Temperature, ThingSpeak, Mobile Application.

\section{INTRODUCTION}

Every year 17.1 million lives are taken away due to an unhealthy diet and physical inactivity, factors which lead to cardiovascular diseases, the world's largest killer. Cardiovascular diseases affect all ages and gender. A heart

Revised Manuscript Received on October 10, 2020.

* Correspondence Author

Juhi K. Patgiri, Department of Biomedical Engineering, North-Eastern Hill University, Shillong, India. Email: patgirijuhikangkan@gmail.com

Arindam Mondal, Department of Biomedical Engineering, North-Eastern Hill University, Shillong, India. Email: arindammondal0202@gmail.com

Gitanjali Kaman, Department of Biomedical Engineering, North-Eastern Hill University, Shillong, India. Email: kamangitanjali483@gmail.com

Pinki Deori, Department of Biomedical Engineering, North-Eastern Hill University, Shillong, India. Email: pinki11deori@gmail.com

Vinayak Majhi, Department of Biomedical Engineering, North-Eastern Hill University, Shillong, India. Email: majhi.vinayak@gmail.com

Sudip Paul*, Department of Biomedical Engineering, North-Eastern Hill University, Shillong, India. Email: sudip.paul.bhu@gmail.com

(C) The Authors. Published by Blue Eyes Intelligence Engineering and Sciences Publication (BEIESP). This is an open access article under the CC BY-NC-ND license (http://creativecommons.org/licenses/by-nc-nd/4.0/) attack is the leading cardiovascular disease [1].

Heart rate is a critical parameter in the functioning of the heart. Therefore, to maintain the heart's health, it is essential to study the heart and health monitoring is required [2].Even it is essential to continuously monitor the health status of a patient having heart-related diseases. Nevertheless, there arise many problems such as in remote places, doctors' availability is the main setback, in hospitals, the doctor may not be available anytime, and in some cases, people may not identify their condition, which leads to the death of the patient. In modern era Internet of Things (IoT)redefines Healthcare, allowing us to innovate new designs and take them to a new level. It is a giant network that connects things and people. The advantage of IoT in Healthcare is endless. Few advantages of IoT in Healthcare include reducing errors, decreased costs, providing better patient experience, homecare etc. [3]. In this paper, we proposed a system using specialized sensors such as temperature sensors (LM35 Temperature sensor) and ECG sensor(ECG module AD8232) to monitor the patient's body temperature and heart rate. These two physiological parameters can easily be monitored and are essential to detect the disease [4]. This will enable the doctors to view patients' health status remotely without being physically present near the patient and necessary treatment. This system will help especially the elders ill patients who are not in the hospital, patients in the remote area, and patients residing in the hospitals to monitor their health conditions [5]. People need not have to travel long distances for a check-up, which saves a lot of time and can help during emergencies. This patient health monitoring device enables the sensors to track the parameters and upload the data collected to the server so that the doctor can quickly check, and necessary treatment can be done at the earliest preventing death rates [6]. The uploaded data can also be stored and this can be used by doctor for future investigations. Our project includes various software and hardware components. The software consists of an IoT platform which is ThingSpeak. The hardware consists of an Arduino Uno microcontroller, ECG Module AD8232, Temperature sensor LM35, LCD Display, and WiFi module ESP8266. Arduino Uno is a microcontroller used to collect data through the sensors and upload the data to the IoT platform through WiFi and display the data in an LCD display. In this project, we measure heart rate form ECG. Electrocardiography(ECG) is a diagnostic technique used to record the electrical activity of the heart [7]. In this technique, the heart's electrical potential is recorded from the body

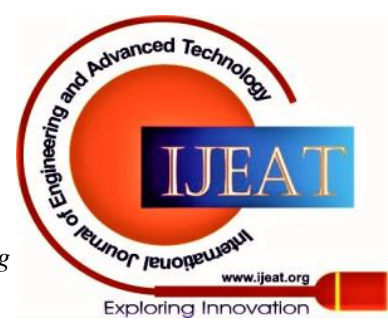




\section{Significant Contribution in Healthcare by using IoT}

surface using a suitable electronic instrument. This instrument is known as an electrocardiograph, and the record taken on the graph paper is called an electrocardiogram [8]. From an electrocardiogram, we can easily calculate the heart rate in the unit of beat/minute [9].

We calculate the value of each ECG graph's time duration or pick to pick the time duration of two ECG graphs then divide by 60 [10]. We also measure the body temperature using the LM35 temperature sensor, which gives us an output value of $10 \mathrm{mV}$ per ${ }^{\circ} \mathrm{C}$ [11]. After that, we convert the temperature value from ${ }^{\circ} \mathrm{C}$ to ${ }^{\circ} \mathrm{F}$. After calculating heart rate values and temperature, both the values are displayed on the 16x2 LCD display module and the values are sent together to the IoT server after every 17 seconds time duration. The data uploaded into ThingSpeak can be shown in a mobile app, so we develop a mobile application and create a webpage [12].

\section{METHODOLOGY}

\section{A. Working Principle of the proposed system}

The IoT project developed is built with Arduino Uno, NodeMCU ESP8266 WiFi Module, AD8232 ECG Module, LM35 Temperature Sensor, 16x2 LCD Display, and other components. The Arduino Uno is interfaced with an AD8232 ECG Module and an LM35 Temperature Sensor so that both the sensors can ECG and temperature data. The AD8232 ECG Module has a $3.5 \mathrm{~mm}$ jack socket to connect with a $3.5 \mathrm{~mm}$ jack plug of a single lead cable with a three-electrode connector[13]. This three-electrode connector is connected with $3 \mathrm{Ag}$-AgCl electrodes by placing them in the patient's limb as lead-I configuration to take ECG data [14]. Then the heart rate value is calculated from the ECG [5]. Calculation of heat rate is done by using the following formula-

Heart rate $=(60 /$ Time duration of a single ECG graph in second) beats per minute

The LM35 Temperature Sensor gives the analog Output as $19 \mathrm{mV}$ per ${ }^{\circ} \mathrm{C}$. For converting ${ }^{\circ} \mathrm{C}$ to ${ }^{\circ} \mathrm{F}$, the following formula is used-

Body temperature $=[\{($ Output voltage of LM35 in mV range/10)*(9/5) $\}+32]^{\circ} \mathrm{F}$

The Arduino Uno is also interfaced with a 16x2 LCD to display the recorded heart rate and body temperature. Moreover, a NodeMCU ESP8266 WiFi Module is interfaced with the Arduino Uno to send those data values to the IoT server ThingSpeak. With this simple yet effective device, the health status of a patient can be monitored. The health-related data, i.e., heart rate and body temperature, are periodically updated to the ThingSpeak platform after every 17 seconds time duration. This data can be further utilized to keep the medical history of the patient. The NodeMCU ESP8266 WiFi module access internet from a local hotspot connection to send data to an IoT server. All the processes are done automatically by the Arduino Uno programmed with a suitable algorithm. After uploading the recorded data to ThingSpeak, it can be shown in the mobile application. The mobile application has been developed using the MIT app inventor. It is an application that allows us to build apps using programming illustrations. It is an open-source web application that uses a graphical interface and block-based coding programs, allowing users to create applications that can be used on smartphones [15]. The main need for app development is to lift the IoT, which results in the MIT inventor, which helps connect devices [16].

\section{B. Electrode placement}

In this project, we calculate heart rate from ECG, measuring from three limbs (LA, RA, RL) surface by placing Ag-AgCl electrodes and EG lead cable as lead-I configuration [17]. The color codes for ECG lead cable are as shown in figure 1.

- Green-Left Arm (LA)

- Red-Right Arm (RA)

- Yellow-right Leg $(R L)$
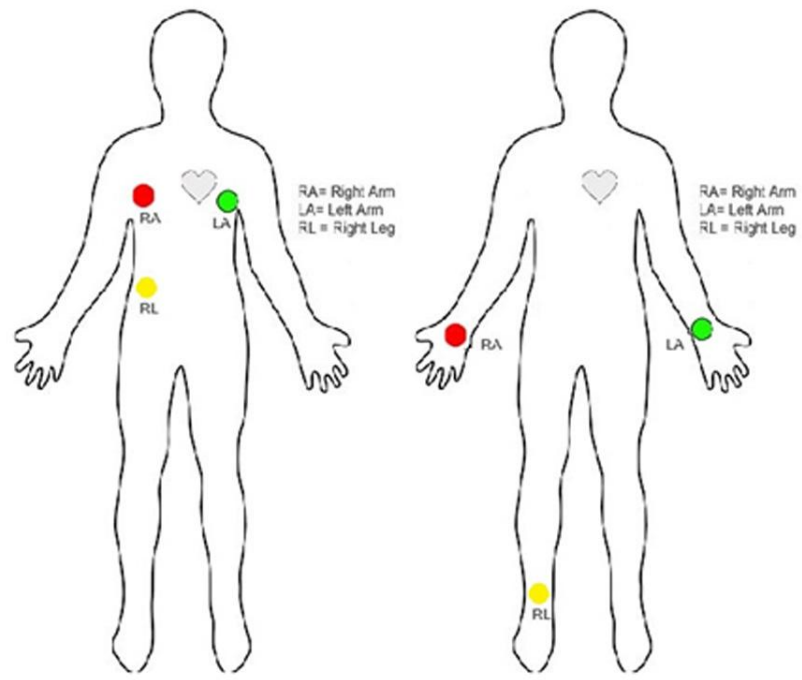

Fig. 1. Electrode placement positions

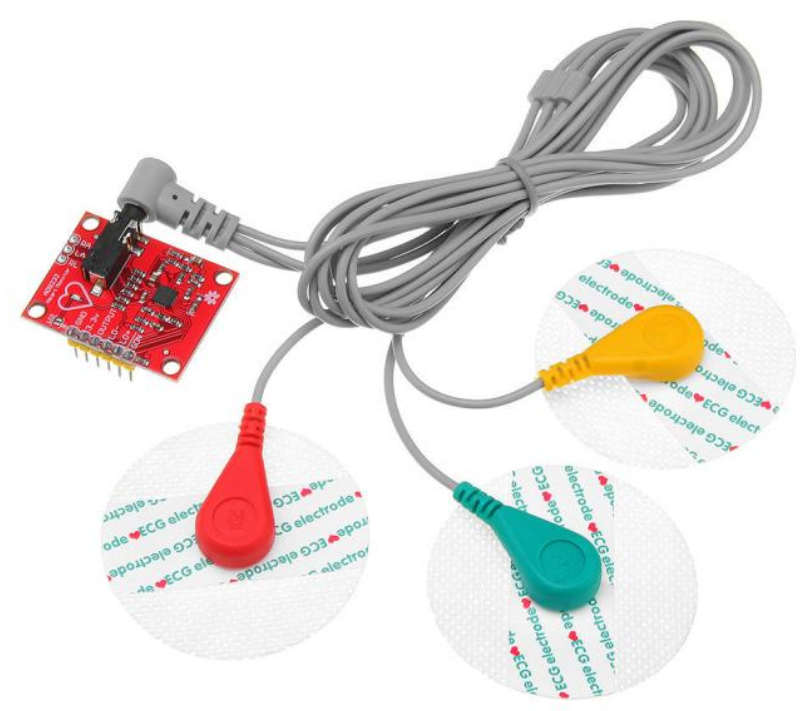

Fig. 2. ECG module AD8232, Electrodes and Cable

\section{THEORETICAL DISCUSSION}

Published By:

Blue Eyes Intelligence Engineering and Sciences Publication

(C) Copyright: All rights reserved.

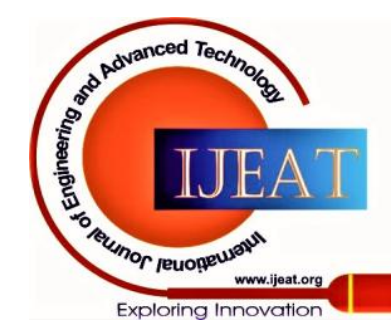


In the block diagram shown in figure 3, the power supply is a 9 volt DC battery, which provides power to the Arduino Uno through the ON/OFF switch. The Output of the AD8232 ECG module and LM35 temperature sensors are connected to the Arduino Uno analog inputs to provide an analog input signal to the Arduino Uno.

These output signals are processed by Arduino Uno using a suitable algorithm. Then the final outputs are displayed on 16x2 LCD as heart rate and temperature. Arduino Uno is also connected with an ESP8266 WiFi module, which accesses the internet from a hotspot connection to send the heart rate and temperature data to an IoT server. A LED is also connected with a digital output port and ground port of the Arduino Uno to blink for each heartbeat during measurement.

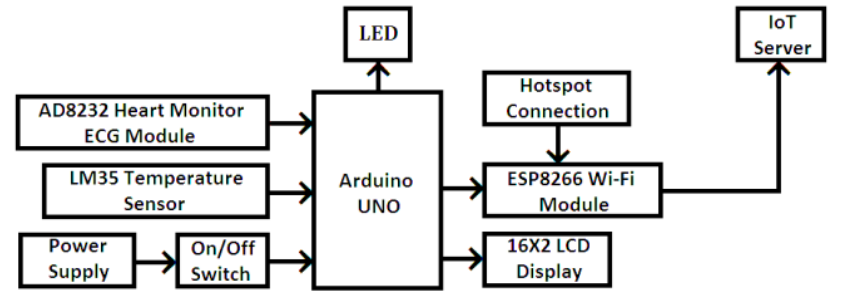

Fig. 3. Block diagram of IoT based heart rate and temperature measurement system

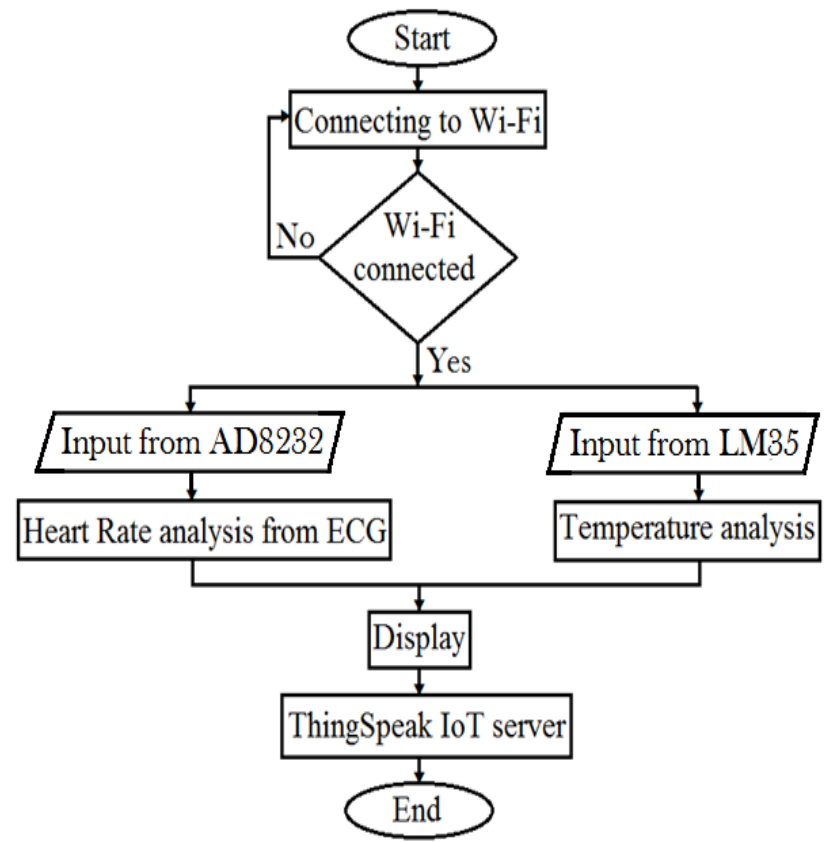

Fig. 4. Flowchart of the complete mechanism

\section{DESCRIPTION OF DESIGNED HARDWARE}

The circuit connection as shown in figure 5, shows all the components connected to the Arduino Uno. The Arduino Uno is a microcontroller board based on the microchip ATmega328P microcontroller [18]. It has 14 digitals pins(of which six can be used as PWM outputs), six analog outputs, a $16 \mathrm{MHz}$ ceramic resonator, a USB connection, and a power jack. It contains everything to support the microcontroller [19]. For measuring the heartbeat, we are using the AD8232 ECG module to measure ECG. We connect the AD8232 ECG module to Arduino Uno by using only three ports of the ECG module. The three ports are- GND, Output, and Vcc. The ECG module's output pin is connected to the analog input port of A0 of the Arduino Uno. The Vcc is connected to 3.3V DC power port of Arduino Uno. Moreover, the ground is connected to the common ground. For measuring the body temperature, we are using the LM35 temperature sensor. LM35 has three pins- Vcc (pin 1), Output (pin 2), and GND (pin 3). The Vcc and GND pins are connected to Vcc and ground, respectively. The LM35 can be operated by a supplied voltage of $4 \mathrm{~V}$ to $20 \mathrm{~V}$, so a $5 \mathrm{~V}$ supply is used from the Arduino Uno board from the $5 \mathrm{~V}$ power port. The Output of the LM35 is connected to the A1 port of the Arduino Uno since the Output from LM35 is analog. Two $10 \mathrm{~K} \Omega$ potentiometers are used in the circuit, of which one is for adjusting contrast, and another is for adjusting brightness. For adjusting contrast, all three terminals are used. One side terminal of the potentiometer is connected with $5 \mathrm{~V}$ of the Arduino Uno, another side is connected to the ground, and the middle terminal is connected to Vo of LCD to display the values of Heart rate and temperature. For adjusting brightness, only two terminals are used, one terminal is connected with $5 \mathrm{~V}$, and another is connected with the LCD's anode terminal. A 16x2 LCD is connected to the Arduino Uno board by connecting its data pins 2 to 5 with the Arduino Uno board. The Rs and E pin of the LCD is connected to digital port 11 and 12 of the Arduino Uno board. The RW pin of the LCD module is grounded. The Vcc pin of the LCD module is connected to 5V DC from the Arduino Uno. The V0 pin of the LCD module is connected to the middle terminal of the $10 \mathrm{~K} \Omega$ potentiometer. Pin A of the LCD module is connected to $5 \mathrm{~V}$ of Arduino Uno via another $10 \mathrm{~K} \Omega$ potentiometer and pin $\mathrm{K}$ of the LCD module to the ground. The ESP8266 WiFi module is connected to the Arduino Uno board to send data to the IoT server. The Vin of the WiFi module is connected to the $5 \mathrm{~V}$ DC from the Arduino Uno while the ground pin is connected to the common ground. The Tx (Transmitter port) and Rx (Receiver port) of the WiFi module is connected to the digital port 9 and 10 of the Arduino Uno board. The +ve terminal of a $9 \mathrm{~V}$ battery is connected with the Arduino via an ON/OFF switch. Moreover the ve terminal is connected to the ground. An LED is also connected. The +ve terminal of LED is connected to the digital port 7 of the Arduino Uno. Furthermore, the -ve terminal is connected to the ground.

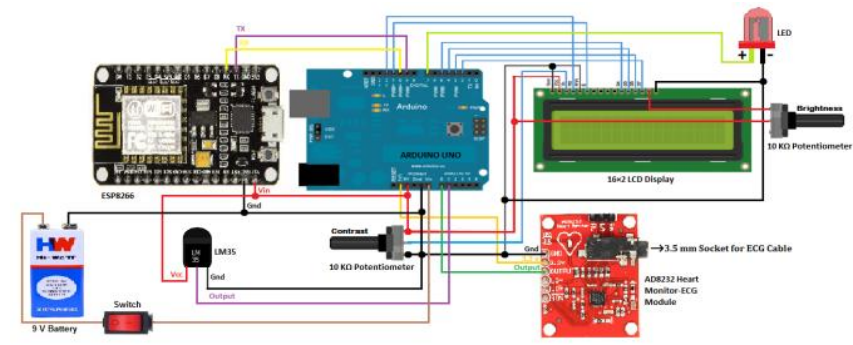

Fig. 5. Circuit diagram of IoT based heart rate and temperature measurement system

\section{MATHEMATICAL CALCULATION}

\section{A. Heart rate calculation}

To calculate the heartrate we measure the time duration of a single ECG graph as shown in figure 6 \& figure 7 and calculate

Published By:

Blue Eyes Intelligence Engineering and Sciences Publication

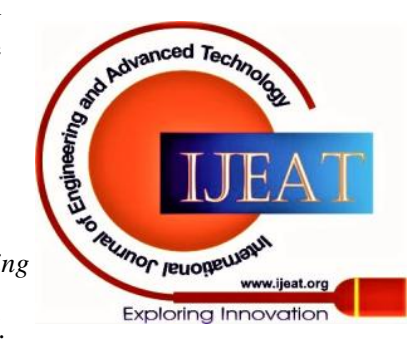




\section{Significant Contribution in Healthcare by using IoT}

the heart rate from this time duration using the algorithm. The basic formula applied in this project for calculating heart rate is as follows:- Heart rate $=(60 /$ Time duration of a single ECG graph in second) Beats per minute

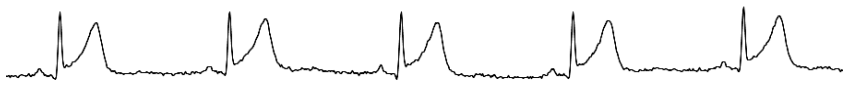

Fig. 6. ECG graph acquisition by AD8232 during an experiment

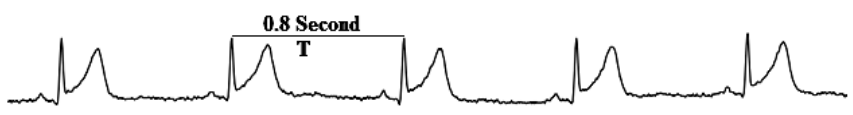

Fig. 7. Time duration measuring from the ECG graph

\section{B. Temperature Calculation}

Basic formula of temperature calculation is as follows-

Temperature $=[\{$ (output voltage of LM35 in $\mathrm{mV}$ range $/ 10) *(9 / 5)\}+32]{ }^{\circ} \mathrm{F}$

\section{RESULT AND DISCUSSION}

The developed IoT based heart rate and temperature measurement device. This device enables to measure heart rate and body temperature. We calculate heart rate from ECG (Electrocardiogram), and the temperature value is converted from Centigrade to Fahrenheit. The result is displayed on the $16 x 2$ LCD and uploaded to the ThingSpeak IoT server. The heart rate value is shown in table 1 where the date and time stamp is coming with heartrate value. The designed hardware setup is shown in figure 8. The LED indicator will blink as per the heartbeat. The sensor output is being transferred to the ThingSpeak and that can be displayed through the ThingsSpeak website by using proper credentials as shown in figure 9 . Through this web site we can also view the graphical plot of the different variance of the heartrate and temperature value. This will help to identify the patents physiological behavior throughout the time. The server value can also be displayed to any customized website by using proper Application Programming Interface (API). This API will help to integrate the IoT servers features into users developed website or mobile application. In this project we also incorporate this IoT output in our customized designed website an also in the developed mobile app using MIT app inventor as shown in figure 10 and 11.

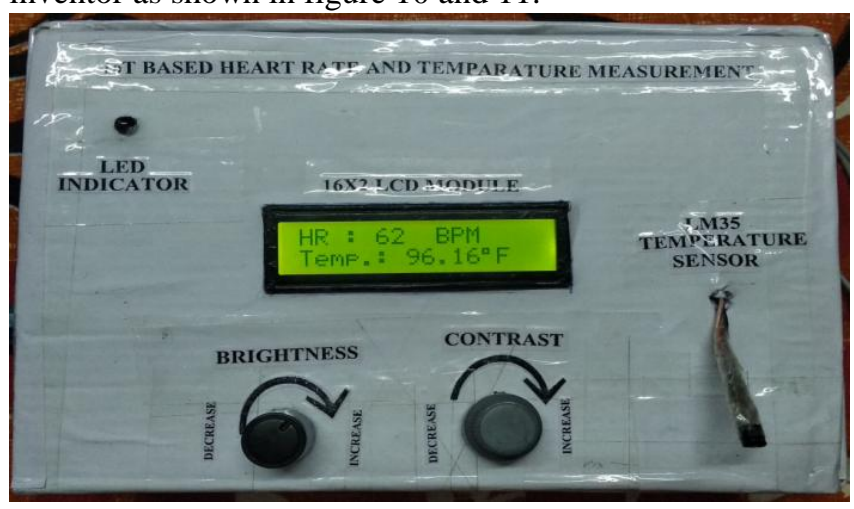

Fig. 8. Result displayed on a 16x2 LCD showing the temperature and heart rate
Table I: Heart Rate value on the IoT server

\begin{tabular}{|l|l|l|}
\hline \multicolumn{2}{|c|}{ Date } & $\begin{array}{c}\text { Heart Rate } \\
\text { (BPM) }\end{array}$ \\
\cline { 1 - 2 } & $\begin{array}{c}\text { Time (As per India } \\
\text { GMT is +0530) }\end{array}$ & \\
\hline $29^{\text {th }}$ September, 2020 & $22: 40: 59$ & 105 \\
\hline $29^{\text {th }}$ September, 2020 & $22: 41: 16$ & 87 \\
\hline $29^{\text {th }}$ September, 2020 & $22: 41: 33$ & 87 \\
\hline $29^{\text {th }}$ September, 2020 & $22: 41: 50$ & 90 \\
\hline $29^{\text {th }}$ September, 2020 & $22: 42: 07$ & 116 \\
\hline $29^{\text {th }}$ September, 2020 & $22: 42: 24$ & 122 \\
\hline $29^{\text {th }}$ September, 2020 & $22: 42: 41$ & 122 \\
\hline $29^{\text {th }}$ September, 2020 & $22: 42: 58$ & 79 \\
\hline $29^{\text {th }}$ September, 2020 & $22: 43: 15$ & 79 \\
\hline $29^{\text {th }}$ September, 2020 & $22: 43: 32$ & 108 \\
\hline $29^{\text {th }}$ September, 2020 & $22: 46: 26$ & 97 \\
\hline $29^{\text {th }}$ September, 2020 & $22: 46: 43$ & 95 \\
\hline $29^{\text {th }}$ September, 2020 & $22: 47: 00$ & 113 \\
\hline $29^{\text {th }}$ September, 2020 & $22: 47: 17$ & 72 \\
\hline $29^{\text {th }}$ September, 2020 & $22: 47: 34$ & 107 \\
\hline $29^{\text {th }}$ September, 2020 & $22: 47: 51$ & 98 \\
\hline $29^{\text {th }}$ September, 2020 & $22: 48: 08$ & 74 \\
\hline $29^{\text {th }}$ September, 2020 & $23: 10: 13$ & 67 \\
\hline $29^{\text {th }}$ September, 2020 & $23: 10: 30$ & 79 \\
\hline $29^{\text {th }}$ September, 2020 & $23: 10: 47$ & 78 \\
\hline $29^{\text {th }}$ September, 2020 & $23: 10: 04$ & 77 \\
\hline $29^{\text {th }}$ September, 2020 & $23: 11: 21$ & 74 \\
\hline $29^{\text {th }}$ September, 2020 & $23: 20: 30$ & 84 \\
\hline $29^{\text {th }}$ September, 2020 & $23: 20: 47$ & 85 \\
\hline $29^{\text {th }}$ September, 2020 & $23: 21: 04$ & 69 \\
\hline $29^{\text {th }}$ September, 2020 & $23: 21: 21$ & 71 \\
\hline $29^{\text {th }}$ September, 2020 & $23: 21: 38$ & 80 \\
\hline $29^{\text {th }}$ September, 2020 & $23: 24: 39$ & 74 \\
\hline $29^{\text {th }}$ September, 2020 & $23: 24: 56$ & \\
\hline & & 69 \\
\hline
\end{tabular}

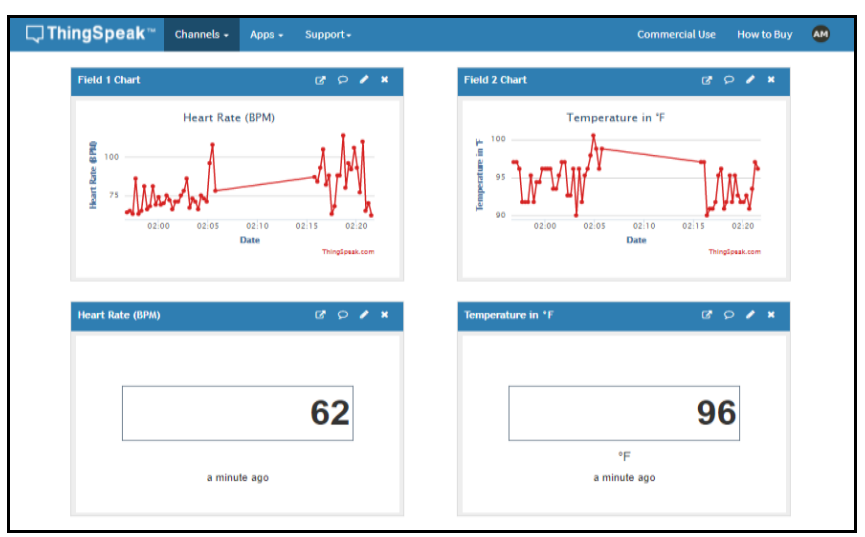

Fig. 9. Result on ThingSpeak website

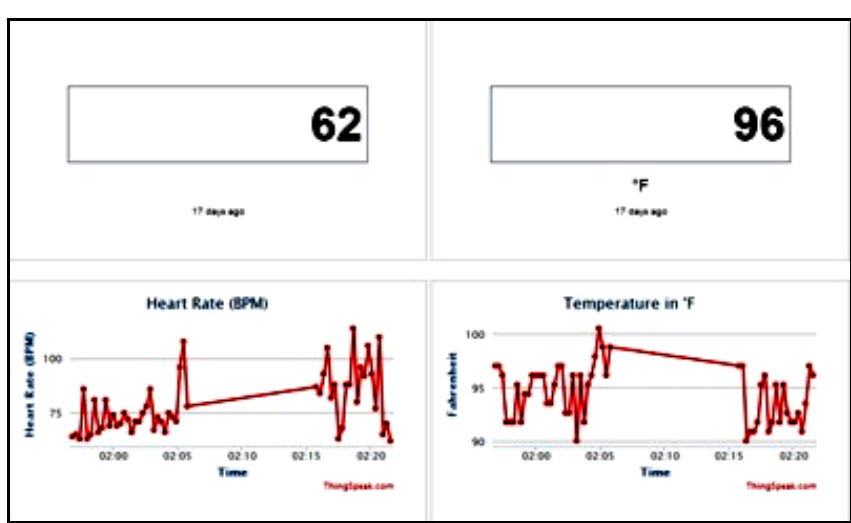

Fig. 10. Final result on our webpage

Published By:

Blue Eyes Intelligence Engineering and Sciences Publication

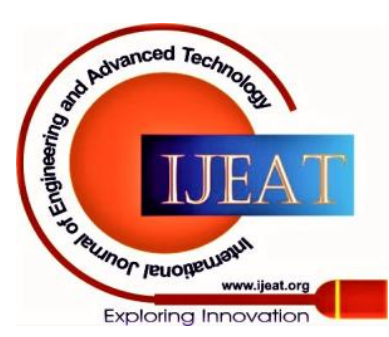



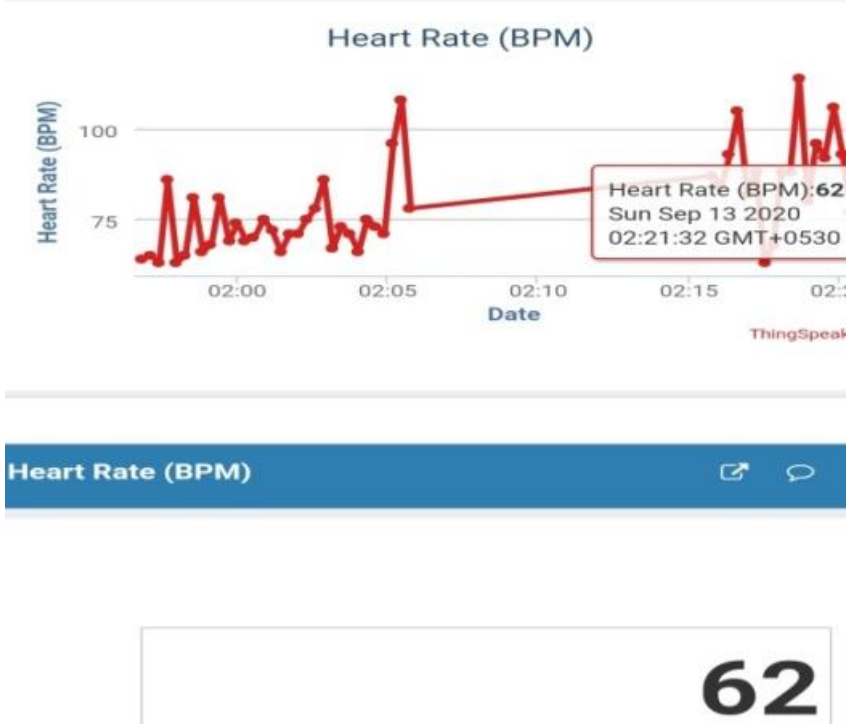

Fig. 11. Screenshot of heartrate displayed in design mobile application
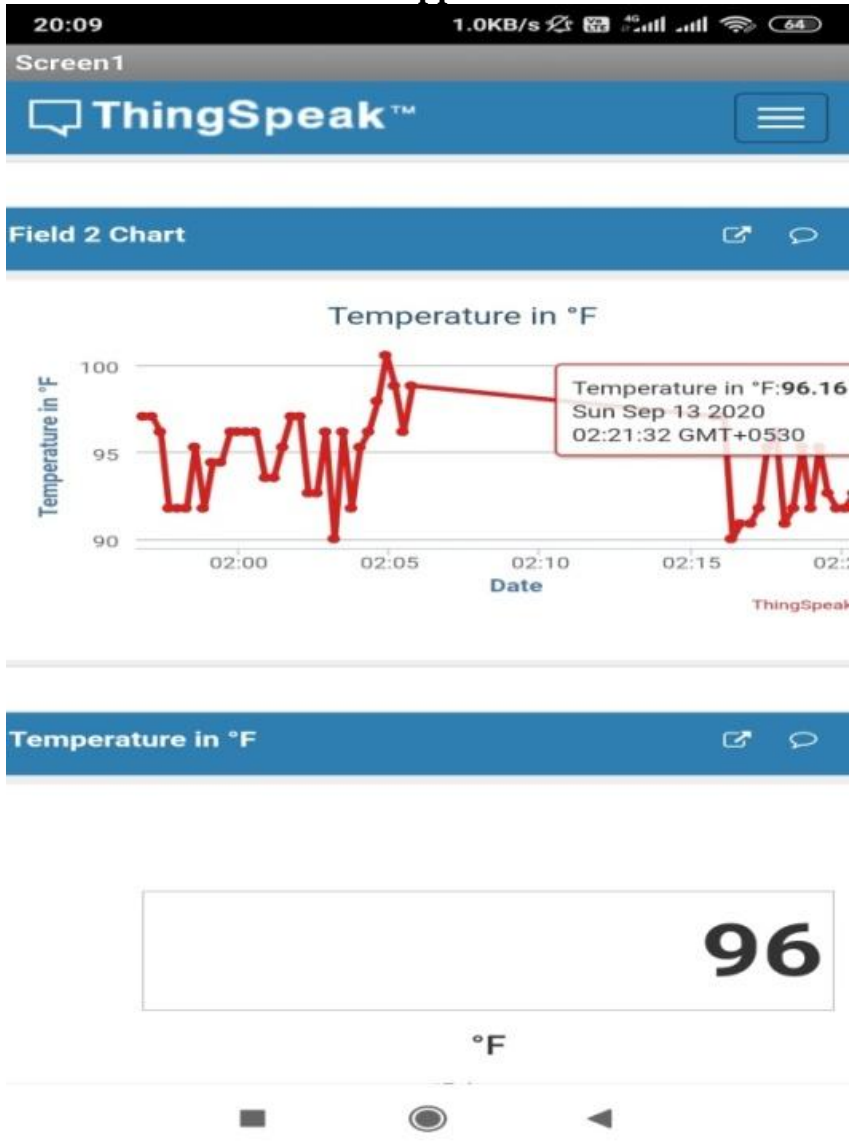

Fig. 12. Screenshot of temperature displayed in design mobile application

\section{CONCLUSION}

A simple patient health monitoring device is developed using sensors and IoT technology, which measures the heart rate and temperature. The proposed system of the patient health monitoring can be highly helpful for old patients, ill patients in remote areas, and emergencies as it can be monitored continuously, recorded, and stored for future purposes. It will be an easy task in emergencies to give first aid to the patients. The graphical view of the considered parameters will help the medical practitioners to get the overview of the patients conditions throughout the time. This variance monitoring is a very essential task to understand the disease behavior. Through this technology we can add more parameters to make this system much effective and supportive for the healthcare practitioners. Further few abnormalities detection mechanism can also be incorporated to get the automatic emergency call by the system in critical condition with the help of Artificial Intelligence with IoT

\section{REFERENCES}

1. Booth, F.W., C.K. Roberts, and M.J. Laye, Lack of exercise is a major cause of chronic diseases. Comprehensive Physiology, 2012. 2(2): p. 1143-1211.

2. Abdelgawad, A., K. Yelamarthi, and A. Khattab. IoT-based health monitoring system for active and assisted living. in International Conference on Smart Objects and Technologies for Social Good. 2016. Springer.

3. Usak, M., et al., Health care service delivery based on the Internet of things: A systematic and comprehensive study. International Journal of Communication Systems, 2020. 33(2): p. e4179.

4. Patil, S. and S. Pardeshi, Health monitoring system using IoT. Int. Res. J. Eng. Technol.(IRJET), 2018. 5(04).

5. Julius, A. and Z. Jian-Min, IoT Based Patient Health Monitoring System Using Lab VIEW and Wireless Sensor Network. International Journal of Science and Research (IJSR), 2017. 6(3).

6. Baudenbacher, F., et al., Smart mobile health monitoring system and related methods. 2015, Google Patents.

7. Hariman, R.J., et al., Method for recording electrical activity of the sinoatrial node and automatic atrial foci during cardiac catheterization in human subjects. The American journal of cardiology, 1980. 45(4): p. 775-781.

8. Wagner, G.S., Marriott's practical electrocardiography. 2001: Lippincott Williams \& Wilkins.

9. Grant, R.P., Clinical electrocardiography. Academic Medicine, 1958. 33(3): p. 242.

10. Madl, T. Network analysis of heart beat intervals using horizontal visibility graphs. in 2016 Computing in Cardiology Conference (CinC). 2016. IEEE.

11. Liu, C., et al. The application of soil temperature measurement by LM35 temperature sensors. in Proceedings of 2011 International Conference on Electronic \& Mechanical Engineering and Information Technology. 2011. IEEE.

12. Pasha, S., ThingSpeak based sensing and monitoring system for IoT with Matlab Analysis. International Journal of New Technology and Research, 2016. 2(6).

13. Briginets, S., et al. Development of a mobile heart monitor based on the ECG module AD8232. in AIP Conference Proceedings. 2018. AIP Publishing LLC.

14. Kakiuchi, T., T. Yoshimatsu, and N. Nishi, New class of $\mathrm{Ag} / \mathrm{AgCl}$ electrodes based on hydrophobic ionic liquid saturated with $\mathrm{AgCl}$. Analytical chemistry, 2007. 79(18): p. 7187-7191.

15. Kumar, R. and M.P. Rajasekaran. An IoT based patient monitoring system using raspberry Pi. in 2016 International Conference on Computing Technologies and Intelligent Data Engineering (ICCTIDE'16). 2016. IEEE.

\section{Published By:}

Blue Eyes Intelligence Engineering and Sciences Publication

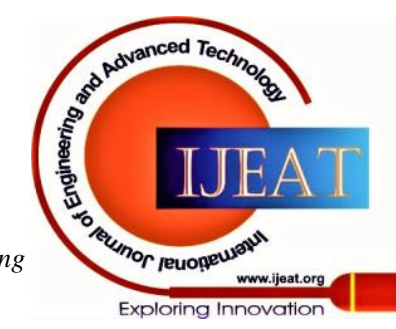


16. Patton, E.W., M. Tissenbaum, and F. Harunani, MIT App Inventor: Objectives, Design, and Development, in Computational Thinking Education, S.-C. Kong and H. Abelson, Editors. 2019, Springer Singapore: Singapore. p. 31-49.

17. Ye, C., M.T. Coimbra, and B.V. Kumar. Investigation of human identification using two-lead electrocardiogram (ECG) signals. in 2010 Fourth IEEE International Conference on Biometrics: Theory, Applications and Systems (BTAS). 2010. IEEE.

18. Badamasi, Y.A. The working principle of an Arduino. in 2014 11th international conference on electronics, computer and computation (ICECCO). 2014. IEEE.

19. Coorporation, A., Atmel atmega328p datasheet. Accessed: Apr, 2011. 26: p. 2018.

\section{AUTHORS PROFILE}

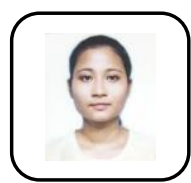

Juhi Kangkan Patgiri is pursuing B.Tech in Biomedical Engineering from Department of Biomedical Engineering, School of Technology, North-Eastern Hill University, Shillong-793022. Her area of interest includes medical instruments and signal processing.

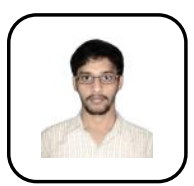

Arindam Mondal completed Diploma in Medical Laboratory Technology from S. A. R. M. Polytechnic, West Bengal State Council of Technical \& Vocational Education \& Skill Development in 2017. He is currently pursuing B.Tech in Biomedical Engineering from Department of Biomedical Engineering, School of Technology, North-Eastern Hill University, Shillong-793022. His area of interest includes medical electronics, biomedical instrumentation, biomedical signal analysis and medical imaging.

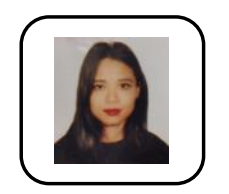

Gitanjali Kaman is pursuing B.Tech in Biomedical Engineering from Department of Biomedical Engineering, School of Technology, North-Eastern Hill University, Shillong-793022. Her areas of interest are biomedical healthcare sector and healthcare management.

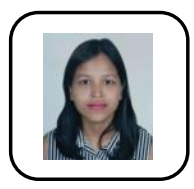

Pinki Deori is pursuing B.Tech in Biomedical Engineering from Department of Biomedical Engineering, School of Technology, North-Eastern Hill University, Shillong-793022. Her areas of interest are biomedical instrumentation and medical imaging technique.

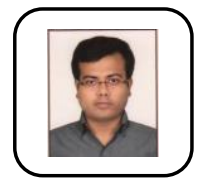

Mr. Vinayak Majhi, is currently working as Junior Research Fellow in IMPRINT-2, a technology development initiative of MHRD and DST in the Department of Biomedical Engineering, NEHU, Shillong. Previously He was working as a Guest Faculty in the Department of Biomedical Engineering, NEHU, Shillong. He completed his B.Tech in Computer Science and Engineering from WBUT, West Bengal, in 2011 and his M. Tech in Computer Science and Engineering from University of Calcutta, West Bengal, India in 2013. Presently he is pursuing his PhD from Department of Biomedical Engineering, NEHU, Shillong. He is specialized in Computational Biology, Neurodynamics, Neurophysiology, Soft Computing, Software Development, Automation, Bioelectronics. Currently he is working on Automatic Detection of Parkinson's Disease based on Ayurvedic Philosophy.

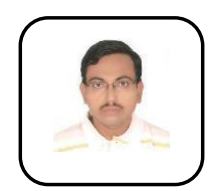

Dr. Sudip Paul: He is currently working as Assistant Professor and Teacher In-Charge in the Department of Biomedical Engineering, NEHU, Shillong. He completed his B-Tech in Biomedical Engineering from West Bengal University of Technology, India and M-Tech in Biomedical Engineering from Banaras Hindu University, India. He completed his PhD from IIT (BHU). He has several research papers in reputed journals in the field of Electrophysiology, Biomedical Instrumentation, Biomedical Signal Processing, Artificial Organ and Rehabilitation System.

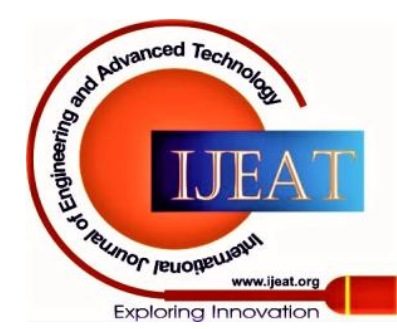

